\title{
Comparison of spinal anesthesia dosage based on height and weight versus height alone in patients undergoing elective cesarean section
}

\author{
Khalid Maudood Siddiqui, Muhammad Asghar Ali, and Hameed Ullah \\ Department of Anesthesiology, Aga Khan University Hospital, Karachi, Pakistan
}

Background: Spinal anesthesia with bupivacaine, typically used for elective and emergency cesarean section, is associated with a significant incidence of hypotension resulting from sympathetic blockade. A variety of dosing regimens have been used to administer spinal anesthesia for cesarean section. The objective of this study was to compare the incidence of hypotension following two different fixed dosing regimens.

Methods: This was a randomized double-blind clinical trial with a two-sided design, 5\% significance level and 80\% power. After approval of the hospital ethics review committee, 60 patients were divided randomly into two groups. In one group, the local anesthetic dose was adjusted according to height and weight, and in the other, the dose was adjusted according to height only.

Results: Sixty women with a singleton pregnancy were included. Of the factors that could affect dose and blood pressure, including age, weight, height, and dose, only height differed between the groups. Mean heart rate was similar between the groups. Hypotension was significantly more frequent with dosage based on height alone than with two-factor dose calculation $(56.7 \%$ vs. $26.7 \%$; $\mathrm{P}=0.018)$.

Conclusions: Adjusting the dose of isobaric bupivacaine to a patient's height and weight provides adequate anesthesia for elective cesarean section and is associated with a decreased incidence and severity of maternal hypotension and less use of ephedrine.

Key Words: Caesarean section, Body height, Body weight, Local anesthetics, Spinal anesthesia.

Corresponding author: Muhammad Asghar Ali, M.D.

Department of Anesthesiology, Aga Khan University Hospital, National

Stadium Road, Karachi 74800, Pakistan

Tel: 92-21-3486-4631, Fax: 92-21-3493-4294

E-mail: asghar.ashraf@aku.edu

Received: July 3, 2015.

Revised: 1st, September 5, 2015; 2nd, September 16, 2015.

Accepted: September 22, 2015.

Korean J Anesthesiol 2016 April 69(2): 143-148

http://dx.doi.org/10.4097/kjae.2016.69.2.143

\section{Introduction}

Spinal anesthesia with bupivacaine is traditionally used in combination with opioids for emergency and elective cesarean section, and provides satisfactory outcomes. However, this strategy is associated with a significant incidence of hypotension resulting from sympathetic blockade [1-3]. Maternal hypotension jeopardizes placental perfusion, compromises fetal outcome, and can cause symptoms such as nausea, vomiting, and dizziness [4,5]. Many spinal anesthesia dosing regimes have been described for cesarean section [6]; while a fixed dosing regimen is preferred by some anesthetists, others adjust the dose based

(c) This is an open-access article distributed under the terms of the Creative Commons Attribution Non-Commercial License (http://creativecommons.org/ licenses/by-nc/4.0/), which permits unrestricted non-commercial use, distribution, and reproduction in any medium, provided the original work is properly cited. 
on patient characteristics. Adjusted dosing is supported by hemodynamic data showing that the time to attain a suitable sensory level for surgery correlates incrementally with height and is inversely related to weight [7].

Previous studies have confirmed that the final level of the block can be predicted by patient height and weight [8]. The optimal dose would allow dermatomal spread but avoid maternal hypotension. In some studies, local anesthetic dose has been adjusted with height alone [9]. However, whether height of the block is related to patient height and weight or height only is controversial. The purpose of this study was to determine the best dosing regimen for adequate anesthesia with minimal side effects.

\section{Materials and Methods}

This study was approved by the Ethics Review Committee of Aga Khan University, and written informed consent was obtained from all patients included in the study. Sixty women with singleton pregnancies and American Society of Anesthesiologists physical status classifications I and II who were scheduled for elective cesarean section were included. Women with a history of pregnancy-induced hypertension, cardiovascular co-morbidities, known central nervous system disease, contraindications to neuraxial block, weight $<50 \mathrm{~kg}$ or $>110 \mathrm{~kg}$, height $>180$ $\mathrm{cm}$ or $<140 \mathrm{~cm}$, and allergy to local anesthetics were excluded. Patients were randomized to the two groups using computergenerated codes sequentially allocated to sealed envelopes.

In the first patient group, the local anesthetic dose was adjusted according to height and weight (Table 1), whereas those in the other group received a local anesthetic dose adjusted ac-

Table 1. Weight- and Height-adjusted 0.5\% Bupivacaine Dosing Regimen for Spinal Anesthesia in Women Undergoing cesarean Section

\begin{tabular}{cccccccccc}
\hline \multirow{2}{*}{$\begin{array}{c}\text { Patient } \\
\text { weight }(\mathrm{kg})\end{array}$} & \multicolumn{8}{c}{ Patient height $(\mathrm{cm})$} \\
\cline { 2 - 10 } & 140 & 145 & 150 & 155 & 160 & 165 & 170 & 175 & 180 \\
\hline 50 & 1.5 & 1.7 & 1.8 & 1.9 & & & & & \\
55 & 1.5 & 1.6 & 1.8 & 1.9 & 2.0 & & & & \\
60 & 1.4 & 1.6 & 1.7 & 1.8 & 2.0 & 2.1 & & & \\
65 & 1.4 & 1.5 & 1.7 & 1.8 & 1.9 & 2.1 & 2.2 & & \\
70 & 1.3 & 1.5 & 1.6 & 1.8 & 1.9 & 2.0 & 2.2 & 2.3 & \\
75 & & 1.4 & 1.6 & 1.7 & 1.9 & 2.0 & 2.1 & 2.3 & 2.4 \\
80 & & 1.4 & 1.5 & 1.7 & 1.8 & 2.0 & 2.1 & 2.2 & 2.4 \\
85 & & & 1.5 & 1.6 & 1.8 & 1.9 & 2.1 & 2.2 & 2.3 \\
90 & & & 1.4 & 1.6 & 1.7 & 1.9 & 2.0 & 2.2 & 2.3 \\
95 & & & & 1.5 & 1.7 & 1.8 & 2.0 & 2.1 & 2.3 \\
100 & & & & 1.5 & 1.7 & 1.8 & 1.9 & 2.1 & 2.2 \\
105 & & & & & 1.6 & 1.7 & 1.9 & 2.0 & 2.2 \\
110 & & & & & & 1.7 & 1.8 & 2.0 & 2.2
\end{tabular}

Values are milliliters. cording to height only (Table 2). Patients were premedicated with intravenous $50 \mathrm{mg}$ ranitidine, $10 \mathrm{mg}$ metoclopramide, and $30 \mathrm{ml}$ oral sodium citrate $30 \mathrm{~min}$ before surgery.

Patients and researchers were blinded to group allocations. The anesthetist who administered the neuraxial block was unblinded. The drugs for each group were prepared in $3 \mathrm{ml}$ syringes.

Our routine perioperative monitoring included continuous $\mathrm{SpO}_{2}$, electrocardiograph, and noninvasive blood pressure monitoring. Hemodynamic variables were monitored every 5 min during surgery after spinal anesthesia was induced (Datex Ohmeda AS, Helsinki, Finland). The level of sensory block was assessed $5 \mathrm{~min}$ after administering the spinal anesthetic.

After infiltrating the skin with $2 \%$ lidocaine, intravenous access was obtained with an $18 \mathrm{G}$ or $16 \mathrm{G}$ wide bore cannula through which all patients were preloaded with a balanced crystalloid solution $(10 \mathrm{ml} / \mathrm{kg})$ over $10 \mathrm{~min}$ before inducing spinal anesthesia. Aseptic measures were used when administering drugs into the spine. Subarachnoid block was obtained with the patient in the sitting position using a $25 \mathrm{G}$ pencil point spinal needle at the L2-3 vertebral inter space. After aspirating cerebrospinal fluid, patients in the first group received $25 \mu \mathrm{g}$ fentanyl $(0.5 \mathrm{ml})$ in isobaric $0.5 \%$ bupivacaine determined according to the dosing regimen described in Table 1, while those in the other group received the same drug solution at $0.05 \mathrm{mg} / \mathrm{cm}$ (Table 2) over 5 seconds. Patients were immediately turned supine and maintained in the wedge position to minimize aortocaval compression. Supplemental oxygen at $4 \mathrm{~L} / \mathrm{min}$ was given to all patients via face mask.

The usual hemodynamic alterations after administration of spinal anesthesia as described in the literature were anticipated and considered, such as bradycardia, hypotension, nausea/ vomiting, and ineffective spinal anesthesia. Bradycardia (heart rate $<60 / \mathrm{min}$ ) was treated with intravenous $0.5 \mathrm{mg}$ atropine, hypotension ( $>20 \%$ decrease in baseline mean arterial pressure [MAP] and heart rate) and nausea, vomiting or dizziness were treated with intravenous $5 \mathrm{mg}$ ephedrine.

Table 2. Bupivacaine Dose and Volume with Respect to Patient Height

\begin{tabular}{ccc}
\hline Patient height $(\mathrm{cm})$ & Dose $(\mathrm{mg})$ & Dose $(\mathrm{ml})$ \\
\hline 140 & 7.0 & 1.4 \\
145 & 7.2 & 1.4 \\
150 & 7.5 & 1.5 \\
155 & 7.7 & 1.5 \\
160 & 8.0 & 1.6 \\
165 & 8.2 & 1.6 \\
170 & 8.5 & 1.7 \\
175 & 8.7 & 1.7 \\
180 & 9.0 & 1.8 \\
\hline
\end{tabular}


Once the sensory block was determined to be effective, surgery was initiated when loss of cold and pinprick sensations in response to ethyl chloride spray were observed bilaterally. A $10^{\circ}$ head-down tilt was employed to improve block height and address ineffective blockade as evaluated at $8 \mathrm{~min}$. A mixture of $50: 50 \mathrm{O}_{2}: \mathrm{N}_{2} \mathrm{O}$ was administered by face mask if discomfort was reported by the patient during surgery. If discomfort persisted, two intravenous boluses of $50 \mu \mathrm{g}$ fentanyl were administered. We converted to general anesthesia if these measures were inadequate.

Sixty subjects (30/group) needed to be included in the study to achieve $80 \%$ power at a $5 \%$ level of significance to detect a $25 \%$ difference in the incidence of hypotension between groups. The incidence of hypotension in two pilot study groups were $34 \%$ and $9 \%$. All statistical analyses were performed using SPSS version 19.0 (IBM Corp., Armonk, NY, USA). Means or medians and frequency/percentage were computed for quantitative and qualitative observations, respectively. Quantitative variables were compared by Mann-Whitney U-test and independent samples t-test, while proportions were compared by chi-square test, and median time to adequate spinal block was compared using the median test. Changes in heart rate and MAP were detected using repeated-measures analysis of variance. A P value $\leq$ 0.05 was considered significant.

Table 3. Patient Demographic Data

\begin{tabular}{lccl}
\hline \multicolumn{1}{c}{ Variables } & $\begin{array}{c}\text { Height/weight dosing } \\
(\mathrm{n}=30)\end{array}$ & $\begin{array}{c}\text { Height-only dosing } \\
(\mathrm{n}=30)\end{array}$ & P value \\
\hline Age $(\mathrm{yr})$ & $29.26 \pm 8.84$ & $29.73 \pm 6.99$ & 0.52 \\
Weight $(\mathrm{kg})$ & $72.4 \pm 12.65$ & $75.31 \pm 11.31$ & 0.35 \\
Height $(\mathrm{cm})$ & $159.4 \pm 5.73$ & $155.86 \pm 6.40$ & $0.027^{*}$ \\
& $159.5[7]$ & $157[9]$ & $0.05^{\dagger}$ \\
Dose & $8.39 \pm 0.81$ & $8.29 \pm 2.00$ & 0.45 \\
\hline
\end{tabular}

Values are mean \pm standard deviation and median [interquartile range]. *Significant at $\mathrm{P}<0.05$ by independent sample $\mathrm{t}$-test. ${ }^{\dagger}$ Mann-Whitney U-test.

\section{Results}

Sixty women with singleton pregnancies were analyzed. Patients' mean age was $29.50 \pm 7.90$ years $(95 \%$ confidence interval [CI], 27.46-31.54), and mean weight and height were .86 $\pm 11.98 \mathrm{~kg}(95 \% \mathrm{CI}, 70.76-76.96)$ and $157 \pm 6.286 \mathrm{~cm}(95 \% \mathrm{CI}$, 156.03-159.27), respectively. Age, weight, and spinal anesthetic dose did not differ between the groups, but mean height did $(\mathrm{P}=0.027)$ (Table 3$)$.

The comparison of height and time to adequate spinal block between the groups is shown in Table 4 . The block was performed at T4 in 24 patients (80\%) in the group whose anesthesia was dosed based on height and weight and in 27 (90\%) in the group with dosages based on height alone. Median time to achieve adequate block in the first group was significantly longer than that for the second group ( $\mathrm{P}=0.005)$. However, block level did not differ between groups.

Mean heart rate did not differ between groups but a significant within-group difference was detected in mean heart rate $(\mathrm{P}<0.05)$. MAP was similar between groups up to $30 \mathrm{~min}$; however, a significant within-group difference was observed ( $\mathrm{P}=0.05$; Figs. 1 and 2).

Bradycardia occurred in one patient receiving an anesthesia dose based on both factors. The incidence of hypotension was significantly higher in the height-alone dosage group than in the two-factor dosage group ( $56.7 \%$ vs. $26.7 \%$; $\mathrm{P}=0.018$ ). More patients receiving height-calculated anesthesia were given ephedrine than in the other group ( $53.3 \%$ vs. $30.6 \%, \mathrm{P}=0.02)$, and a large median dose was administered ( $10.5 \mathrm{mg}$ vs. $7.5 \mathrm{mg}, \mathrm{P}=0.042$ ).

Four patients with two-factor anesthesia dosage had episodes of vomiting, whereas three such cases were observed in the other group (Fig. 3). None of the patients were converted to general anesthesia due to inadequate subarachnoid block.

Mean time to effective block (min) did not differ between the groups (Table 5). Patients receiving two-factor anesthesia dosages tended to take a longer time to be discharged from the recovery room than those in the other group. No differences in

Table 4. Comparison of Height and Time to Adequate Block between the Groups

\begin{tabular}{|c|c|c|c|c|c|}
\hline \multirow{2}{*}{ Height of block* } & \multicolumn{2}{|c|}{$\begin{array}{l}\text { Height/weight dosing } \\
\qquad(\mathrm{n}=30)\end{array}$} & \multicolumn{2}{|r|}{$\begin{array}{l}\text { Height-only dosing } \\
\qquad(\mathrm{n}=30)\end{array}$} & \multirow{2}{*}{ Total } \\
\hline & $\mathrm{n}(\%)$ & Median time in minutes (IQR) & $\mathrm{n}(\%)$ & Median time in minutes (IQR) & \\
\hline T3 & $0(0 \%)$ & - & $1(3.3 \%)$ & - & $1(1.7 \%)$ \\
\hline $\mathrm{T} 4$ & $24(80 \%)$ & $8[6]$ & $27(90 \%)$ & $5[4]$ & $51(85 \%)$ \\
\hline T5 & $4(13.3 \%)$ & $8[53]$ & $1(3.3 \%)$ & - & $5(8.3 \%)$ \\
\hline T6 & $2(6.7 \%)$ & $11[0]$ & $0(0 \%)$ & - & $2(3.3 \%)$ \\
\hline $\mathrm{T} 10$ & $0(\%)$ & - & $1(\%)$ & - & $1(1.7 \%)$ \\
\hline Time to adequate block & - & $8[5]$ & - & $5[4]$ & 0.005 \\
\hline
\end{tabular}

Values are numbers (\%) and medians [interquartile range]. $* \mathrm{P}=0.472$, Fisher's exact test; and $\mathrm{P}<0.01$; median test applied. 


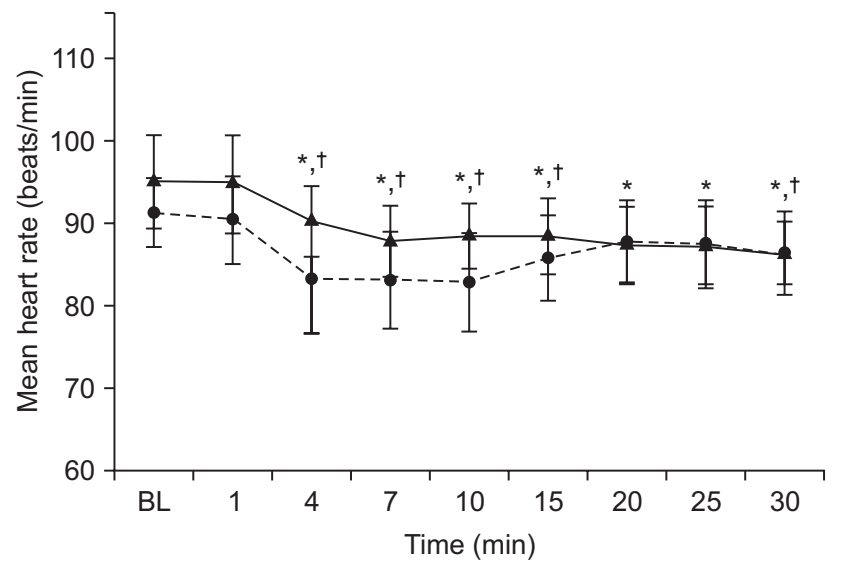

Fig. 1. Comparison of mean heart rate between patients receiving anesthesia dosages based on height and weight $(n=30$, triangles, solid line) and those whose dose was calculated based on height alone ( $\mathrm{n}=$ 30 , circles, dotted line). Error bars are $95 \%$ confidence intervals. No difference was observed between groups but a significant difference was observed from baseline ${ }^{*} \mathrm{P}<0.05$ in the height-weight group and ${ }^{\dagger} \mathrm{P}<0.05$ in the height-alone group.

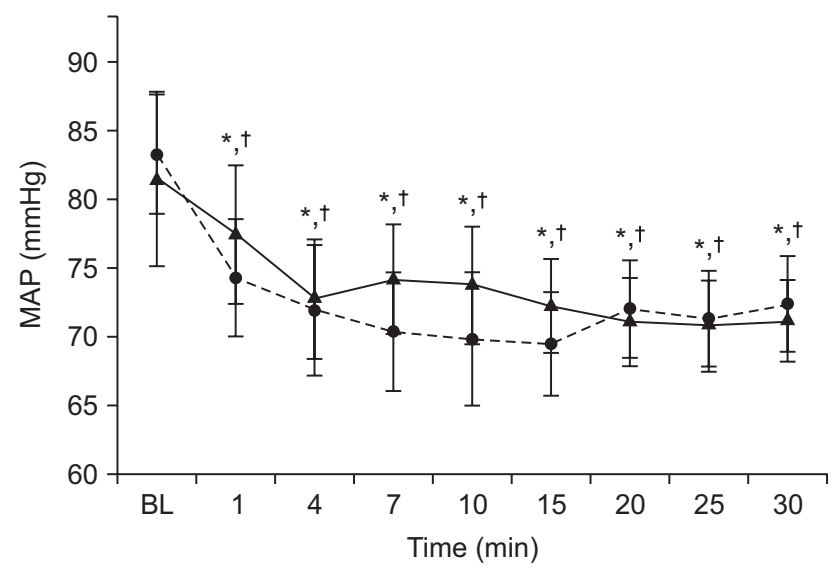

Fig. 2. Comparison of mean arterial pressure (MAP) between patients receiving anesthesia dosages based on height and weight $(\mathrm{n}=30$, triangles, solid line) and those whose dose was calculated based on height alone ( $n=30$, circles, dotted line). Error bars are $95 \%$ confidence intervals. No difference was observed between the groups but a significant difference was observed from baseline $* \mathrm{P}<0.05$ in the height-weight group and ${ }^{\dagger} \mathrm{P}<0.05$ in the height-alone group. the 1 and 5 min fetal APGAR scores were observed between the groups.

\section{Discussion}

Spinal anesthesia is generally used during cesarean sections because it keeps the mother conscious, decreases problems related to complex intubation and maternal aspiration pneumonitis, and facilitates effective postoperative pain relief. However, spinal anesthesia can cause hypotension [10,11], which leads to in utero placental hypoperfusion and instigates a severe drop in intervillous blood flow with the possibility of fetal acidemia $[12,13]$. A wide range of spinal anesthesia dosing regimes has been used during cesarean section [6]. A direct correlation with height and an inverse correlation with weight have been suggested based on pharmacodynamic data collected at the time to onset of an adequate sensory level for surgery and has been validated by clinical observations [14].

In this prospective, double-blind, randomized study, we compared two spinal anesthesia dosing regimes for cesarean section based on either patient height plus weight or height alone. The onset time for suitable sensory blockade was longer in the height plus weight group, although it was associated with decreased prevalence and acuteness of maternal hypotension and a lower

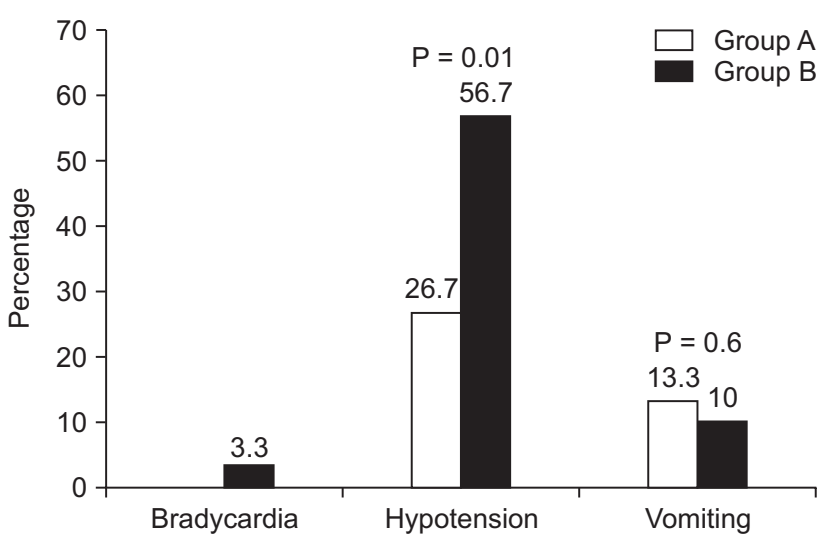

Fig. 3. Comparison of complications between the groups.

Table 5. Comparisons of Hypotension Treatment, Time to Reverse Block, and Discharge from the Recovery Room

\begin{tabular}{|c|c|c|c|}
\hline & $\begin{array}{l}\text { Height/weight dosing } \\
\qquad(\mathrm{n}=30)\end{array}$ & $\begin{array}{l}\text { Height-only dosing } \\
\qquad(\mathrm{n}=30)\end{array}$ & P value \\
\hline \multicolumn{4}{|l|}{ Hypotension treated with ${ }^{\ddagger}$} \\
\hline Ephedrine & $8(26.7 \%)$ & $16(53.3 \%)$ & $0.03^{*}$ \\
\hline Fentanyl & $5(16.7 \%)$ & $2(6.7 \%)$ & 0.22 \\
\hline $\mathrm{N}_{2} \mathrm{O}$ & $2(6.7 \%)$ & $0(0 \%)$ & 0.49 \\
\hline Time to block reversal $(\mathrm{min})^{\dagger}$ & $115[21]$ & $110[11]$ & 0.081 \\
\hline Time to discharge from recovery room $(\mathrm{min})^{\dagger}$ & $130[21]$ & $125[11]$ & 0.084 \\
\hline
\end{tabular}

Values are numbers (\%) and medians [interquartile range]. $* \mathrm{P}<0.05 .{ }^{\dagger} \mathrm{Mann}-\mathrm{Whitney} \mathrm{U}$-test. ${ }^{\ddagger} \mathrm{Chi}$-square test. 
ephedrine requirement. This group tended to spend more time in the recovery room before discharge than the other group but the difference was not statistically significant. Norris [14] reported that height has no effect on hyperbaric spinal anesthesia. However, theoretically, hypotension severity should be affected by the quantity and volume of local anesthetic agent used. Harten et al. [15] reported that the incidence and severity of maternal hypotension decrease after adjusting the dose of hyperbaric bupivacaine to the patient's height and weight, which is comparable with our results.

In contrast to other studies, Nagata et al. [16] of Japan and Chung et al. [2] of Korea demonstrated that pregnant women require less local anesthetic compared to their nonpregnant counterparts and that a height-adjusted dosing regime avoids the risk of maternal hypotension. However, height-based dosing was not compared with that based on height plus weight in these studies.

Our results suggest that adjusting the anesthetic dose to height and weight improves the safety of spinal anesthesia. Although the incidence and acuteness of maternal hypotension declined in the height and weight group, its association with improved fetal outcome was not verified.

In addition, variables affecting the spread and duration of regional anesthesia, including but not limited to basicity, total dose, type of local anesthetic solution, injection site, and patient positioning must be considered, as they may affect the final outcome. Although spinal anesthesia is effective and safe, all corroborative factors should be considered.

The highest incidence of hypotension in women undergoing cesarean section is observed under spinal anesthesia. Nonmodifiable risk factors include female sex, age $>50$ years, body mass index $>35 \mathrm{~kg} / \mathrm{m}^{2}$, and the nature of the surgery. Two other modifiable risk factors are high bupivacaine dose and a sensory block level $\geq \mathrm{T} 5$ [17]. In this study, all variables were comparable, except patient height.

Anesthesia may need to be augmented with intravenous narcotics if sensory block is insufficient or if the surgeon encounters an unexpected event that requires more time, increasing anesthesia duration. Many studies have shown that various additives, such as morphine and fentanyl enhance the spread and duration of spinal block via multiple administration routes [18]. We found no difference in the use of fentanyl between according to anesthesia dosage calculation method.

The incidence of hypotension during spinal anesthesia for cesarean section is as high as $80 \%$ despite fluid preloading, lateral uterine displacement, and use of vasopressor agents [19]. Preventing and managing hypotension related to spinal anesthesia remains a difficult issue, and no single approach is optimal. Intravenous ephedrine during spinal anesthesia in women undergoing cesarean section decreases the incidence of nausea and vomiting [20]. Current local obstetric anesthesia practices are established on a fixed dose of bupivacaine for subarachnoid block without narcotics, except at some urban hospitals where fentanyl is available and perioperative hypotension and bradycardia are common. The deleterious effects of spinal anesthesia during cesarean section are more profound when the spinal anesthesia dose is not calculated logically. In this study, less ephedrine was used when the spinal bupivacaine dose was calculated in relation to patient height and weight, which decreased the incidence of hypotension, nausea, and vomiting.

Thus, we conclude that the isobaric $0.5 \%$ bupivacaine dosing regimen should be based on patient height and weight and that $25 \mu \mathrm{g}$ fentanyl should be added to achieve adequate anesthesia for cesarean sections while minimizing the untoward side effects of maternal hypotension with reduced use of vasopressors.

\section{References}

1. Michie AR, Freeman RM, Dutton DA, Howie HB. Subarachnoid anaesthesia for elective caesarean section. A comparison of two hyperbaric solutions. Anaesthesia 1988; 43: 96-9.

2. Chung CJ, Bae SH, Chae KY, Chin YJ. Spinal anaesthesia with $0.25 \%$ hyperbaric bupivacaine for Caesarean section: effects of volume. Br J Anaesth 1996; 77: 145-9.

3. Rout CC, Akoojee SS, Rocke DA, Gouws E. Rapid administration of crystalloid preload does not decrease the incidence of hypotension after spinal anaesthesia for elective caesarean section. Br J Anaesth 1992; 68: 394-7.

4. Corke BC, Datta S, Ostheimer GW, Weiss JB, Alper MH. Spinal anaesthesia for Caesarean section. The influence of hypotension on neonatal outcome. Anaesthesia 1982; 37: 658-62.

5. Marx GF, Cosmi EV, Wollman SB. Biochemical status and clinical condition of mother and infant at cesarean section. Anesth Analg 1969; 48: 986-94.

6. Boyne I, Varveris D, Harten J, Brown A. National survey of dose of hyperbaric bupivacaine for elective caesarean section under spinal anaesthesia. Int J Obstet Anaesth 2000; 13: 20-5.

7. Schnider TW, Minto CF, Bruckert H, Mandema JW. Population pharmacodynamic modeling and covariate detection for central neural blockade. Anesthesiology 1996; 85: 502-12. 
8. McCulloch WJ, Littlewood DG. Influence of obesity on spinal analgesia with isobaric 0.5\% bupivacaine. Br J Anaesth 1986; 58: 610-4.

9. Danelli G, Zangrillo A, Nucera D, Giorgi E, Fanelli G, Senatore R, et al. The minimum effective dose of $0.5 \%$ hyperbaric spinal bupivacaine for cesarean section. Minerva Anestesiol 2001; 67: 573-7.

10. Rout CC, Rocke DA. Prevention of hypotension following spinal anesthesia for cesarean section. Int Anesthesiol Clin 1994; 32 : 117-35.

11. Schnider SM, Levinson G. Anesthesia for cesarean section. In: Anesthesia for Obstetrics. Edited by Schnider SM, Levinson G: Baltimore, Williams and Wilkins. 1987, pp 159-78.

12. Roberts SW, Leveno KJ, Sidawi JE, Lucas MJ, Kelly MA. Fetal acidemia associated with regional anesthesia for elective cesarean delivery. Obstet Gynecol 1995; 85: 79-83.

13. Robson SC, Boys RJ, Rodeck C, Morgan B. Maternal and fetal haemodynamic effects of spinal and extradural anaesthesia for elective caesarean section. Br J Anaesth 1992; 68: 54-9.

14. Norris MC. Height, weight, and the spread of subarachnoid hyperbaric bupivacaine in the term parturient. Anesth Analg 1988; 67: 555-8.

15. Harten JM, Boyne I, Hannah P, Varveris D, Brown A. Effects of a height and weight adjusted dose of local anaesthetic for spinal anaesthesia for elective Caesarean section. Anaesthesia 2005; 60: 348-53.

16. Nagata E, Yoshimine K, Minoda Y, Kawaguchi Y, Sakamoto M, Takehara A. Comparison of $8 \mathrm{mg}$ and 10 mg hyperbaric bupivacaine during spinal anesthesia for cesarean section in Japanese parturients. Masui 2004; 53: 131-6.

17. Chinachoti T, Tritrakarn T. Prospective study of hypotension and bradycardia during spinal anesthesia with bupivacaine: incidence and risk factors, part two. J Med Assoc Thai 2007; 90: 492-501.

18. Masoudifar M, Aghadavoudi O, Rezvani M, Mashayekhi N. The effect of intravenous morphine on the level of spinal anesthesia with lidocaine. Med Arh 2012; 66: 80-3.

19. Rout CC, Rocke DA. Prevention of hypotension following spinal anesthesia for cesarean section. Int Anesthesiol Clin 1994; 32 : 117-35.

20. Kol IO, Kaygusuz K, Gursoy S, Cetin A, Kahramanoglu Z, Ozkan F, et al. The effects of intravenous ephedrine during spinal anesthesia for cesarean delivery: a randomized controlled trial. J Korean Med Sci 2009; 24: 883-8. 